\title{
Es gibt nichts, was es nicht gibt!
}

\section{Nothing is Impossible!}

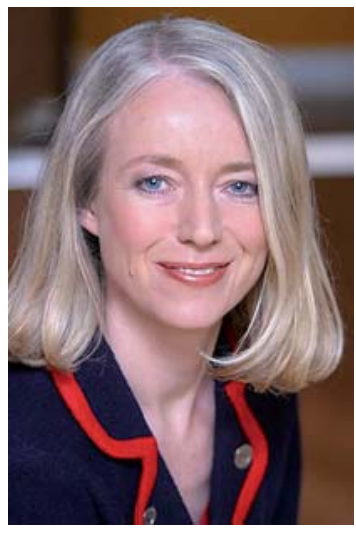

Prof. Dr. Christiane Bayerl
Es gibt keine Allergie gegen...? Fällt Ihnen eine Substanz, ein Nahrungsmittel, ein Medikament ein, zu der oder dem Sie noch keine allergologische Kasuistik gelesen haben? Es scheint nun gerade die Saison der Artischocken in der Herbst-Gourmetküche zu sein. In diesem Zusammenhang wurde mir die Frage gestellt, ob es eine Artischockenallergie gibt. Zunächst fällt auf, dass die Pflanze zu den Korbblütlern (Asteraceae) zählt. Im beruflichen Umfeld bei Ernte und Verarbeitung von Artischocken sind allergische Rhinitis und Bronchitis mehrfach beschrieben. Kreuzreaktionen existieren zu Parietaria-judaica-Pollen [1], dem Glaskraut aus der Familie der Brennnesselgewächse. Sind Artischocken bei nutritiver Aufnahme allergologisch bedenklich? In der Tat, es finden sich Kasuistiken und Fallsammlungen mit Hinweisen darauf, dass es sich um ungewöhnliche klinische Fälle handelt mit der Symptomatik allergische Rhinitis und Asthma nach dem Verspeisen von Artischocken. Die Erstbeschreibung stammt aus Neapel aus dem Jahr 2000 und berichtet über positives spezifisches IgE im Serum, analysiert mithilfe des REAST (reverse enzyme allergosorbent test) [2]. Aus Israel wurde 2003 über ein lebensbedrohliches Quincke-Ödem der Zunge nach Verzehr von Artischocken berichtet [3]. Ein aus Artischocken und Kräutern gebrauter Likör ist unter der Bezeichnung Cynar bekannt. Wegen der Artischockeninhaltsstoffe gilt er als verdauungsfördernd und wird als Digestif gereicht - hierzu findet sich keine Kasuistik.

Zur Verwirrung aufgrund der Namensähnlichkeit kann die Pflanze Jerusalem Artischocke (Helianthus tuberosus) führen, die auch Topinambur genannt wird und mit den Sonnenblumen-Spezies verwandt ist. Auch die Jerusalem Artischocke zählt zu der Familie der Asteraceae. Die stärkereiche Knolle schmeckt süßlich und erinnert von der Konsistenz an Artischockenböden. Sie wird roh als Salat oder frittiert wie Kartoffeln genossen. Eine Kasuistik beschreibt eine allergische Rhinitis im Frühling mit oralem Allergiesyndrom auf Äpfel, Kirschen, Pfirsiche, Haselnuss und rohe Jerusalem Artischocke. Gefunden wurde eine IgEmediierte Nahrungsmittelallergie auf Topinambur aufgrund einer Sensibilisierung auf ein 17kDa-Protein, das zur Familie der Bet v1-homologen Allergene zählt. Der Apfel verliert üblicherweise seine Allergenität - wenn gut entkernt beim Kochen. Im Gegensatz zu anderen Bet v1Homologen ist das Bet v1-ähnliche Allergen der Jerusalem Artischocke immunologisch thermostabil und die Symptome, die in Verbindung mit dem Verzehr der rohen Jerusalem Artischocke stehen, sind schwer [4]. Ein Branntwein kann aus den Topinambur-Wurzeln hergestellt werden, der Badischer Rossler genannt wird und gegen Magenverstimmung helfen soll. Bisher hat er keine allergologische Berühmtheit erlangt, aber alles ist möglich!

Ihre

Christiane Bayerl

\section{Literatur}

1 Miralles JC, Garcia-Sells J, Bartolomé B, Negro JM. Occupational rhinitis and bronchial asthma due to artichoke (Cynara Scolymus). Ann Allergy Asthma Immunol 2003; 91: 92-95

2 Romano C, Ferrara A, Falagiani P. A case report to globe artichoke and other clinical cases of rare food allergy. J Investig Allergol Clin Immunol 2000; 10: $102-104$

3 Gadban H, Gilbey P, Talmon Y, Samet A. Acute edema of the tongue: a life-threatening condition. Ann Otol Rhinol Laryngol 2003; 112: 651-653

4 Doyen $V$, Leduc $V$, Ledent $C$ et al. Allergy to Jerusalem artichoke due to immediate IgE reaction to Bet v1like allergen. Ann Allery Asthma Immunol 2011; 107: $540-541$
Bibliografie

DOI http://dx.doi.org/

10.1055/s-0032-1309514

Akt Dermatol 2012; 38: 417

(c) Georg Thieme Verlag KG

Stuttgart · New York

ISSN 0340-2541

Korrespondenzadresse

Prof. Dr. med. Christiane Bayerl

Klinik für Dermatologie

und Allergologie Wiesbaden

HSK, Wilhelm Freseniusklinik

Städtisches Lehrkrankenhaus

der Universität Mainz

Aukammallee 39

65191 Wiesbaden

Christiane.Bayer!@

HSK-Wiesbaden.de 